\title{
Editorial
}

\section{Peroral Cholangiopancreatoscopy: New Advances Bring New Concerns}

\author{
Marta Gravito-Soares Nuno Almeida \\ Gastroenterology Department, Centro Hospitalar e Universitário de Coimbra, Coimbra, Portugal; \\ Faculty of Medicine, University of Coimbra, Coimbra, Portugal
}

Keywords

Cholangioscopy · Pancreatoscopy $\cdot$ Indeterminate biliopancreatic strictures · Advances · Concerns

\section{Colangiopancreatoscopia Peroral: Novos Avanços Trazem Novas Preocupações}

\section{Palavras Chave}

Colangioscopia $\cdot$ Pancreatoscopia $\cdot$ Estenoses

biliopancreáticas indeterminadas · Avanços · Preocupações

Direct visualization of the biliary and pancreatic ducts has become indispensable in a selected group of pancreatobiliary conditions that represent a high diagnostic and therapeutic challenge not easily resolved by conventional techniques [1]. One of the major challenges includes the evaluation of indeterminate biliopancreatic strictures, regarding malignancy concern $[1,2]$. Despite available methods of indirect visualization of the pancreatobiliary tract, such as endoscopic ultrasonography, computed tomography, magnetic resonance imaging, and endoscopic

\section{KARGER}

E-Mail karger@karger.com www.karger.com/pjg
(C) 2018 Sociedade Portuguesa de Gastrenterologia. Published by S. Karger AG, Basel

Karcer

Open access

This article is licensed under the Creative Commons AttributionNonCommercial-NoDerivatives 4.0 International License (CC BYNC-ND) (http://www.karger.com/Services/OpenAccessLicense). Usage and distribution for commercial purposes as well as any distribution of modified material requires written permission. retrograde cholangiopancreatography (ERCP) using brush cytology and/or intraductal blind biopsy, up to $30 \%$ of pancreatobiliary strictures remain indeterminate [1]. Cholangiocarcinoma and tumor of the pancreatic duct have an inauspicious prognosis, with a 5-year survival rate of less than $5 \%[3,4]$. Since cholangiocarcinoma often shows superficial mucosal spread [5], the early and accurate diagnosis of preneoplastic and operable lesions could reasonably improve prognosis $[3,4]$. On the other hand, a precise diagnosis is required to avoid unnecessary surgery in patients with benign stenosis [2].

Peroral cholangioscopy is performed using a cholangioscope that is advanced through the duodenoscope accessory channel (indirect peroral cholangioscopy) or an ultra-slim upper endoscope that is directly inserted into the biliary tract (direct peroral cholangioscopy) [6]. Over the past decades, significant improvements have been observed in these techniques. In the 1970s, mother-daughter systems were the first methods allowing direct visualization of the biliary tract using a mother duodenoscope and a daughter cholangiopancreatoscope $[5,6]$. Howev$\mathrm{er}$, the need for 2 endoscopists, the labor-intensive procedure, scope fragility, and poor resolution of endoscopic image have become important drawbacks. Recently, the 
development of catheter-based cholangioscopy systems (CCS), as an extension of ERCP duodenoscope, improved visualization and durability; in addition, it requires only 1 operator [6]. CCS allows high diagnostic accuracy in the differentiation between benign and malignant lesions, target biopsy under direct visualization, and therapeutic procedures, such as lithotripsy for difficult biliary stones $[1,6,7]$.

Pancreatic intraductal examination may be more difficult than the biliary tract due to the relatively narrow caliber and tortuosity of the pancreatic duct. Peroral pancreatoscopy was first described in 1997 to evaluate carcinoma in situ of the pancreas [8]. Since then, further applications of this technique in the diagnostic yield are indeterminate stricture of the main pancreatic duct and the suspicion of intraductal papillary mucinous neoplasia with diagnostic accuracy, sensitivity, and specificity of 88 , 68 , and $87 \%$, respectively [9].

Regarding diagnosis of biliary lesions, brush cytology and standard forceps biopsy obtained by indirect visualization under fluoroscopic guidance of the biliary tract have a limited diagnostic accuracy (39-54\%) with low sensitivity (6-51\%) and specificity (55\%) $[2,5,6,10,11]$. Recent systematic reviews and meta-analyses evaluated the diagnostic power of peroral cholangioscopy for malignant biliary stricture based on visual impression and CCS-guided biopsies, with a success rate of $90-100 \%$ [10, $12,13]$. Although visual criteria suggesting malignancy are not yet standardized, they include some worrisome features, such as dilated and tortuous vessels (also called tumor vessels), intraductal nodular or papillary masses, and irregular mucosal surface pattern $[2,5,6]$. The reported accuracy of visual diagnosis was $78-89 \%$, with $84-$ $95 \%$ sensitivity and $82 \%$ specificity [12]. However, the low specificity of direct visualization alone implies pathologic analysis for definitive diagnosis [2]. Most studies reported an adequate quality sampling in $82-97 \%$ of biopsies obtained by CCS $[6,11,12,14]$ with a diagnostic accuracy, sensitivity, and specificity of $49-93 \%, 49-82 \%$, and $97-98 \%$, respectively $[6,10-12,14,15]$. The diagnostic accuracy of biliary malignancy increases to $96 \%$ when combining cholangioscopic visualization and biopsy [9, $10,12,14]$. In addition, both visual impression and cholangioscopy-guided biopsies showed low sensitivity for extrinsic lesions $[2,10]$.

Even though peroral cholangioscopy has been considered a safe procedure, concerns about its safety have arisen recently [6]. Several complications have been reported (up to 7\%), including cases of cholangitis, bacteremia, liver abscess, pancreatitis, and bleeding. The most com- monly reported complication is acute cholangitis (up to $14 \%)$ related to intraductal saline irrigation during cholangiopancreatoscopy $[16,17]$. However, serious complications have been described in up to $1 \%$, such as air embolism and perforation [12]. Therefore, antibiotic prophylaxis, $\mathrm{CO}_{2}$ insufflation, and biliary drainage in selected cases have been used to minimize some of these potential adverse events $[6,17]$.

In this issue of GE - Portuguese Journal of Gastroenterology, Pereira et al. [18] describe the diagnostic impact of SpyGlass ${ }^{\mathrm{TM}}$ direct visualization system (SGDVS) in addition to ERCP in indeterminate pancreatobiliary strictures. They prospectively enrolled 12 cholangioscopies and 1 pancreatoscopy with a technical success rate of $100 \%$. Among patients in whom SGDVS-guided biopsies were possible to obtain (85\%), the diagnostic accuracy was $55 \%$. On the other hand, the diagnostic accuracy of visual impression was $85 \%$. Encompassing visual impression, pathology findings, and patients' follow-up, SGDVS was able to exclude malignancy in $69 \%$ of patients $(56 \%$ by SGDVS-guided biopsy), but it was able to confirm malignancy in only $31 \%$ of cases $(75 \%$ by SGDVS-guided biopsy). Although severity was considered mild in all adverse events, the complication rate for this diagnostic procedure was not negligible (31\%), with pancreatitis (19\%) and cholangitis (13\%) being the most common adverse events. The authors concluded that SGDVS is an effective procedure for the evaluation of pancreatobiliary strictures, changing the clinical outcome in difficult cases with acceptable safety [18].

Despite the increasing clinical use of SGDVS with a high success rate $[10,12,16]$, there are still limited data regarding its efficacy and safety, which is related to studies' heterogeneity in outcome and adverse event definition, interoperator variability, endoscopist experience, different peroral cholangioscopy systems used, and the number of biopsies performed [10]. Recent systematic reviews and meta-analyses revealed that endoscopists' visual impression has a higher accuracy than cholangioscopy-guided biopsy, which was also verified by Pereira et al. [18], probably in relation to higher sensitivity of visual impression compared to biopsy due to technical challenges of sampling. Therefore, the need for increasing the number of biopsies and even the use of rapid onsite evaluation (ROSE) has been suggested [10, 12, 19]. By the contrary, low specificity of visual impression, which is always a subjective parameter, limits its isolated use to diagnose indeterminate biliary strictures. Indeed, the high sensitivity of visual impression and the high specificity of biopsy underline the importance of using a combined ap- 
proach to increase the diagnostic accuracy of pancreatobiliary malignancy $[10,12,13]$. Thus, visual impression is useful in detecting malignant lesions and cholangioscopy-guided biopsy in confirming malignant lesions [13]. Few studies evaluate how CCS can modify patient management $[11,20]$. Pereira et al. [18] found that CCS was more useful in excluding malignancy and avoiding unnecessary surgery than confirming malignancy. In spite of the use of periprocedural prophylactic antibiotics, cholangitis along with pancreatitis remain the most worrying adverse events in most studies, as reported by Pereira et al. [17, 18].

Beyond undoubted advantages for the evaluation of indeterminate pancreatobiliary strictures, peroral chol- angiopancreatoscopy remains an expensive time-consuming procedure with several technical limitations and not negligible complications in the context of a diagnostic procedure. Future innovations are needed for feasible, safe, and less-invasive systems with a larger field of view, image-enhanced cholangioscopy (chromocholangioscopy), and a larger working channel to improve diagnostic and therapeutic accuracy as well as optimize prophylactic strategies to minimize complications.

\section{Disclosure Statement}

The authors have no conflicts of interest to declare.

\section{References}

1 Voaklander R, Kim E, Brown WH, et al: An overview of the evolution of direct cholangioscopy techniques for diagnosis and therapy. Gastroenterol Hepatol 2016;12:433-437.

$\checkmark 2$ Pereira P, Peixoto A, Andrade P, et al: Peroral cholangiopancreatoscopy with the SpyGlass ${ }^{\circledR}$ system: what do we know 10 years later. J Gastrointest Liver Dis 2017;26:165-170.

3 McLean L, Patel T: Racial and ethnic variations in the epidemiology of intrahepatic cholangiocarcinoma in the United States. Liver Int 2006;26:1047-1053.

4 Bosetti C, Bertuccio P, Negri E, et al: Pancreatic cancer: overview of descriptive epidemiology. Mol Carcinog 2012;51:3-13.

5 Itoi T: Cholangioscopy; in Jonnalagadda SS (ed): Gastrointestinal Endoscopy: New Technologies and Changing Paradigms. New York, Springer, 2015, pp 23-37.

6 Ghersi S, Fuccio L, Bassi M, et al: Current status of peroral cholangioscopy in biliary tract diseases. World J Gastrointest Endosc 2015;7: 510-517.

7 Franzini TA, Moura RN, de Moura EG: Advances in therapeutic cholangioscopy. Gastroenterol Res Pract 2016;2016:5249152.

8 Uehara H, Nakaizumi A, Tatsuta M, et al: Diagnosis of carcinoma in situ of the pancreas by peroral pancreatoscopy and pancreatoscopic cytology. Cancer 1997;79:454-461.
-9 Kurihara T, Yasuda I, Isayama H, et al: Diagnostic and therapeutic single-operator cholangiopancreatoscopy in biliopancreatic diseases: prospective multicenter study in Japan. World J Gastroenterol 2016;22:1891-1901.

-10 Navaneethan U, Hasan MK, Lourdusamy V, et al: Single-operator cholangioscopy and targeted biopsies in the diagnosis of indeterminate biliary strictures: a systematic review. Gastrointest Endosc 2015;82:608-614.e2.

11 Imanishi M, Ogura T, Kurisu Y, et al: A feasibility study of digital single-operator cholangioscopy for diagnostic and therapeutic procedure (with videos). Medicine (Baltimore) 2017;96:e6619.

12 Korrapati P, Ciolino J, Wani S, et al: The efficacy of peroral cholangioscopy for difficult bile duct stones and indeterminate strictures: a systematic review and meta-analysis. Endosc Int Open 2016;4:E263-E275.

13 Sun X, Zhou Z, Tian J, et al: Is single-operator peroral cholangioscopy a useful tool for the diagnosis of indeterminate biliary lesion? A systematic review and meta-analysis. Gastrointest Endosc 2015;82:79-87.

14 Chen YK, Parsi MA, Binmoeller KF, et al: Single-operator cholangioscopy in patients requiring evaluation of bile duct disease or therapy of biliary stones (with videos). Gastrointest Endosc 2011;74:805-814.
15 Navaneethan U, Hasan MK, Kommaraju K, et al: Digital, single-operator cholangiopancreatoscopy in the diagnosis and management of pancreatobiliary disorders: a multicenter clinical experience (with video). Gastrointest Endosc 2016;84:649-655.

16 Tringali A, Lemmers A, Meves V, et al: Intraductal biliopancreatic imaging: European Society of Gastrointestinal Endoscopy (ESGE) technology review. Endoscopy 2015;47:739753.

17 Sethi A, Chen YK, Austin GL, et al: ERCP with cholangiopancreatoscopy may be associated with higher rates of complications than ERCP alone: a single-center experience. Gastrointest Endosc 2011;73:251-256.

18 Pereira P, Vilas-Boas F, Peixoto A, et al: How SpyGlass $^{\mathrm{TM}}$ may impact ERCP practice and patient management. GE Port J Gastroenterol 2017, DOI: $10.1159 / 000481859$.

19 Varadarajulu S, Bang JY, Hasan MK, et al: Improving the diagnostic yield of single-operator cholangioscopy-guided biopsy of indeterminate biliary strictures: ROSE to the rescue? (with video). Gastrointest Endosc 2016;84: 681-687.

20 Alameel T, Bain V, Sandha G: Clinical application of a single-operator direct visualization system improves the diagnostic and therapeutic yield of endoscopic retrograde cholangiopancreatography. Can J Gastroenterol 2013; 27:15-19. 